\title{
The role of iron in the pathophysiology and treatment of chronic hepatitis C
}

\author{
Leslie Price MD, Kris V Kowdley MD
}

\begin{abstract}
L Price, KV Kowdley. The role of iron in the pathophysiology and treatment of chronic hepatitis C. Can J Gastroenterol 2009;23(12):822-828.

Increased hepatic iron content may be observed in patients with chronic hepatitis $\mathrm{C}$ infection, and may contribute to disease severity. The presence of hemochromatosis gene mutations is associated with increased hepatic iron accumulation and may lead to accelerated disease progression. Hepatic iron depletion has been postulated to decrease the risk of hepatocellular carcinoma in patients with cirrhosis due to chronic hepatitis C. It is possible that iron depletion stabilizes or improves liver histology and slows disease progression in these individuals. The present article reviews the prevalence and risk factors for hepatic iron overload in chronic hepatitis $\mathrm{C}$, with emphasis on the available data regarding the efficacy of iron depletion in the treatment of this common liver disease.
\end{abstract}

Key Words: Hemochromatosis; Hepatitis C; Iron overload

T $\mathrm{t}$ is estimated that 3.2 million people in the United States and 170 million individuals worldwide have hepatitis C $(1,2)$. A majority of these patients develop chronic disease, and the hepatitis $\mathrm{C}$ virus (HCV) is now known to be a major cause of cirrhosis and hepatocellular carcinoma (HCC). The goal of medical therapy is to achieve normalization of serum transaminases and prolonged clearance of HCV RNA - also known as a sustained virological response (SVR). However, current treatment regimens that use pegylated interferon and ribavirin achieve an SVR in only $40 \%$ to $50 \%$ of patients with a genotype 1 infection - the most common strain of HCV (3). Therefore, several alternative or adjuvant therapies have been explored as a means to improve antiviral response or to delay the progression of liver disease in patients who do not respond to pegylated interferon therapy. Iron depletion has been one such treatment, and has been the focus of several therapeutic trials.

\section{PATHOPHYSIOLOGY OF LIVER IRON DEPOSITION}

The role of hepatic iron overload in the pathophysiology of chronic liver disease associated with HCV has been a topic of debate for several years. Excess hepatic iron has been postulated as a source of reactive oxygen species that may lead to liver injury and hepatic fibrosis via several mechanisms. Hydroxyl radicals are known to cause oxidation of lipids, lipoproteins, proteins, DNA and other cellular components (4).

\author{
Le rôle du fer dans la physiopathologie et le \\ traitement de l'hépatite $\mathrm{C}$ chronique
}

\begin{abstract}
On peut observer une augmentation de la teneur en fer hépatique chez les patients atteints d'une infection par l'hépatite $\mathrm{C}$ chronique, ce qui peut contribuer à la gravité de la maladie. La présence de mutations du gène d'hémochromatose s'associe à une accumulation accrue du fer hépatique et peut accélérer la progression de la maladie. Il est également postulé que la déplétion du fer hépatique réduit le risque de carcinome hépatocellulaire chez les patients ayant une cirrhose imputable à une hépatite $\mathrm{C}$ chronique. Chez ces personnes, il se peut que la déplétion du fer stabilise ou améliore l'histologie du foie et ralentisse la progression de la maladie. Le présent article contient une analyse de la prévalence et des facteurs de risque de surcharge de fer hépatique en cas d'hépatite $\mathrm{C}$ chronique et s'attarde aux données disponibles au sujet de l'efficacité de la déplétion du fer dans le traitement de cette maladie hépatique courante.
\end{abstract}

Hepatic oxidative DNA damage, signified by elevated levels of 8-hydroxy-2'-deoxyguanosine (8-OHdG), has been strongly and positively associated with increased hepatic iron stores in patients with chronic hepatitis C (CHC) (5). Reactive oxygen species generated by iron deposition may also activate hepatic stellate cells, which stimulate collagen deposition and fibrosis (6). These data suggest that excess iron deposition may be a key component of hepatic oxidative stress and the development of fibrosis.

A possible direct mechanism for iron overload in $\mathrm{CHC}$ has been recently proposed by Nishina et al (7) in male transgenic mice harbouring the HCV polyprotein. These FL-N/35 transgenic mice exhibit decreased hepcidin expression in the liver, accompanied by an increase in ferroportin expression in the duodenum, spleen and liver. Thus, HCV proteins may directly lead to decreased hepcidin transcription and increased ferroportin expression, leading to increased duodenal iron transport, macrophage iron release and hepatic iron accumulation (7). In individuals with $\mathrm{CHC}$, hepcidin messenger RNA levels in the liver have been found to be positively correlated with hepatic iron accumulation $(8,9)$. A positive relationship between hepcidin gene expression and hepatic iron content suggests appropriate regulation of hepcidin in response to hepatic iron stores, but it is unclear whether this response is the same in uninfected individuals. Others have suggested that excess hepatic iron deposition is simply a result of turnover from damaged hepatocytes (10). However, Fujita et al (11) have shown that patients

Center for Liver Disease, Virginia Mason Medical Center, Seattle, Washington, USA

Correspondence: Dr Kris V Kowdley, Center for Liver Disease, Virginia Mason Medical Center,1201 9th Avenue, Seattle, Washington 98101,

USA. Telephone 206-341-1255, fax 206-341-1932, e-mail kris.kowdley@ummc.org

Received for publication March 10, 2009. Accepted March 11, 2009 
with chronic hepatitis $\mathrm{B}$ and $\mathrm{C}$ exhibit similar degrees of necroinflammation, despite significantly elevated total iron scores in $\mathrm{CHC}$ patients compared with chronic hepatitis $\mathrm{B}$ patients. Presently, the precise mechanism involved in the process of liver iron accumulation in $\mathrm{CHC}$, and its impact on the course and progression of $\mathrm{CHC}$ disease, remains unclear.

Although the underlying general mechanisms for iron deposition in the liver among patients with HCV have yet to be elucidated, it is clear that $\mathrm{CHC}$ is associated with liver iron accumulation. Di Bisceglie et al (12) initially reported that $36 \%$ of patients with $\mathrm{CHC}$ had elevated serum iron values and increased stainable iron in Kupffer cells and hepatocytes. A subsequent larger study of $209 \mathrm{CHC}$ patients (13) demonstrated liver iron accumulation in $42 \%$ of patients, with the majority exhibiting only mild liver iron accumulation (35.4\%). However, a significant relationship was found between the severity of histological activity based on METAVIR classification and macrophagic and/or hepatocytic iron deposition (13). Liver iron accumulation was also more frequent in patients with cirrhosis than in those without cirrhosis (15 of 19 [78.9\%] versus 72 of 190 [37.9\%], respectively; $\mathrm{P}=0.004$ ) (13). Conversely, Olynyk et al (14) found that the mean ( \pm SD) hepatic iron concentration (HIC) in cirrhotic and noncirrhotic patients was similar $(722 \pm 137 \mu \mathrm{g} / \mathrm{g}$ versus $735 \pm 82 \mu \mathrm{g} / \mathrm{g}$, respectively; P not significant), and iron deposition was present in both Kupffer cells and hepatocytes. Based on these studies, it is apparent that hepatitis $\mathrm{C}$ is associated with liver iron accumulation and that the pattern is a mixed picture of deposition in hepatocytes and reticuloendothelial cells.

\section{CHC, HEMOCHROMATOSIS GENE MUTATIONS AND LIVER IRON ACCUMULATION}

There is a complex relationship among hepatic iron deposition, hemochromatosis gene (HFE) mutations and disease severity in patients with $\mathrm{CHC}$. A recent large study from the Hepatitis $\mathrm{C}$ Long-Term Treatment against Cirrhosis (HALT-C) cohort found a positive association between HFE mutations and increased hepatic iron in 363 patients (15). Several other studies (16-20) have found that heterozygous C282Y or H63D mutations are associated with hepatic iron loading in $\mathrm{CHC}$ patients. The significance of increased iron loading in these patients and its role in the development of advanced fibrosis remains controversial, with a positive association in some studies $(16,17,21-23)$ and a negative association in others (13,24-28). Several studies have found that both C282Y and H63D mutations are associated with higher grades of inflammation $(23)$, more severe fibrosis $(16,21,23)$ or progression to cirrhosis $(16,21,23)$; however, others $(17,22)$ have suggested that heterozygous $\mathrm{H} 63 \mathrm{D}$ mutations - in contrast to $\mathrm{C} 282 \mathrm{Y}$ mutations - play little or no role in hepatic iron deposition. Gehrke et al (22) found no association between homozygosity or heterozygosity for the H63D mutation and liver fibrosis. In contrast, we previously reported an OR of 22 for the presence of bridging fibrosis or cirrhosis in heterozygous H63D-positive individuals with $\mathrm{HCV}$ infection of at least 15 years duration (16). Erhardt et al (21) found an OR of 3.6 for cirrhosis and 3.1 for fibrosis in heterozygous H63D-positive individuals. Finally, Geier et al (23) found a significant association between heterozygous H63D mutation and hepatic fibrosis, with an OR of 1.97. By contrast, Bonkovsky et al (15) found no significant effect of any HFE mutation (H63D and C282Y) on liver fibrosis among subjects in the HALT-C study, although it should be noted that all patients in this cohort had advanced fibrosis.

The evidence for an association between increased disease severity in C282Y homozygote and heterozygote individuals is stronger. However, similar to H63D mutations, some studies $(16,17,21-23)$ have found a positive association, while others have not (13,24-28). Smith et al (17) found that C282Y heterozygotes had a higher mean fibrosis staging score than wild type patients (3.6 versus $1.5 ; \mathrm{P}=0.01$ ). Cirrhosis was also present more often in individuals with the HFE mutation (40\%) than in those without the mutation $(8.7 \%)(\mathrm{P}=0.01)$. Similarly, we found that any HFE mutation (C282Y and H63D) was strongly associated with bridging fibrosis or cirrhosis in individuals with compensated liver disease (OR 18; 95\% CI 1.7 to 193) (16). The OR for the presence of advanced fibrosis in association with the C282Y mutation was 30 (95\% CI 1.8 to 484) compared with 22 (95\% CI 1.8 to 267) for the H63D mutation (16). However, there was no significant difference in the prevalence of HFE mutations between patients with compensated liver disease and those with end-stage liver disease (16). Gehrke et al (22) did not find an association between H63D mutations and fibrosis, although there was an association between $\mathrm{C} 282 \mathrm{Y}$ mutations and advanced fibrosis or cirrhosis, with an OR of 2.5 (95\% CI 1.0 to 6.3; P<0.05). Another study (23) found a strong association between the C282Y mutation and hepatic fibrosis (OR 4.58; 95\% CI 1.13 to $18.52 ; \mathrm{P}=0.026$ ). Finally, Erhardt et al (21) found a significant association between heterozygous $\mathrm{C} 282 \mathrm{Y}$ mutation and cirrhosis, with an OR of 5.9 (95\% CI 1.6 to 22.6 ; $\mathrm{P}<0.009$ ). Thus, the bulk of the evidence suggests that heterozygous $\mathrm{C} 282 \mathrm{Y}$ individuals with chronic HCV infection are more likely to have more severe hepatocellular injury and fibrosis. By contrast, Thorburn et al (24) found no association between HFE mutations and more advanced liver disease, and Lal et al (25) concluded that the HFE mutation plays a minor role in hepatic iron accumulation in individuals with hepatitis $\mathrm{C}$ cirrhosis. Finally, Hohler et al (28) found no evidence for increased fibrosis in C282Y heterozygotes compared with sex- and age-matched controls.

Several studies have also examined the relationship between HFE mutations and $\mathrm{HCC}$ in patients with $\mathrm{CHC}$, with some describing a positive association $(29,30)$ and others finding no association (31,32). Cauza et al (29) found that C282Y homozygotes with $\mathrm{HCV}$ had a 19 -fold increased risk of HCC, but heterozygotes did not. Hellerbrand et al (30) found an increased frequency of heterozygous $\mathrm{C} 282 \mathrm{Y}$ mutations in patients with HCC but no history of hemochromatosis (12.4\%) compared with cirrhotic $(3.7 \%)$ and healthy controls $(4.8 \%)(\mathrm{P}<0.05)$. However, Boige et al (32) found that the prevalence of $\mathrm{C} 282 \mathrm{Y}$ heterozygote mutations was similar in patients with and without HCC ( $5 \%$ versus 4\%; $\mathrm{P}=0.65$ ). Therefore, the data must be considered inconclusive regarding the association between HFE mutations and the development of HCC in CHC (33).

\section{ADJUVANT PHLEBOTOMY}

Effect of adjuvant phlebotomy with interferon therapy in treatment-naive individuals

Several early reports showed an inverse relationship between hepatic iron content and the response to interferon monotherapy $(14,34,35)$. This observation prompted several studies 
TABLE 1

Summary of studies examining iron depletion therapy in interferon (IFN) treatment-naive individuals

\begin{tabular}{|c|c|c|c|c|c|c|c|c|c|}
\hline \multirow[b]{2}{*}{$\begin{array}{l}\text { Author } \\
\text { (reference) }\end{array}$} & \multicolumn{2}{|c|}{ Patients, n } & \multirow[b]{2}{*}{$\begin{array}{l}\text { IFN } \\
\text { treatment }\end{array}$} & \multicolumn{2}{|c|}{$\begin{array}{l}\text { End treatment response, } \\
\text { n (\%) }\end{array}$} & \multicolumn{2}{|c|}{$\begin{array}{c}\text { Sustained } \\
\text { virological response, } \\
\mathrm{n}(\%) \\
\end{array}$} & \multicolumn{2}{|c|}{$\begin{array}{l}\text { End biochemical } \\
\text { response; sustained bio- } \\
\text { chemical response, } \mathrm{n}(\%)\end{array}$} \\
\hline & IFN & $\begin{array}{c}\text { Iron } \\
\text { depletion } \\
+ \text { IFN }\end{array}$ & & IFN & $\begin{array}{c}\text { Iron } \\
\text { depletion } \\
\text { + IFN }\end{array}$ & IFN & $\begin{array}{l}\text { Iron } \\
\text { depletion } \\
+ \text { IFN }\end{array}$ & IFN & $\begin{array}{c}\text { Iron } \\
\text { depletion } \\
+ \text { IFN }\end{array}$ \\
\hline $\begin{array}{l}\text { Fontana et al } \\
\text { (36) }\end{array}$ & 42 & 40 & $\begin{array}{l}3 \times 10^{6} \mathrm{U} \text { IFN-alpha } 2 \mathrm{~b} \\
3 \text { times weekly for } 6 \text { months }\end{array}$ & 7 (17) & $15(38)$ & $3(7)$ & 7 (18) & $\begin{array}{c}20(48) \\
6(14)\end{array}$ & $\begin{array}{l}25(63) \\
11(28)\end{array}$ \\
\hline $\begin{array}{l}\text { Fargion et al } \\
\text { (37) }\end{array}$ & 57 & 57 & $\begin{array}{l}6 \times 10^{6} \cup \text { IFN-alpha- } 2 \mathrm{~b} \\
3 \text { times weekly for } \\
4 \text { months, then } 3 \times 10^{6} \mathrm{U} \\
3 \text { times weekly for } 8 \text { months }\end{array}$ & $12(21)$ & $18(32)$ & $9(16)$ & $16(28)$ & $\begin{array}{l}18(32) \\
15(26)\end{array}$ & $\begin{array}{l}24(42) \\
19(33)\end{array}$ \\
\hline $\begin{array}{l}\text { Piperno et al } \\
\text { (18) }\end{array}$ & 61 & 20 & $\begin{array}{l}3 \times 10^{6} \mathrm{U} \text { IFN-alpha- } 2 \mathrm{~b} \text { twice } \\
\text { weekly for } 12 \text { months }\end{array}$ & $21(34)$ & $1(5)$ & NR & $0(0)$ & $\begin{array}{l}21(34) ; \\
13(21)\end{array}$ & $\begin{array}{l}1(5) \\
1(5)\end{array}$ \\
\hline $\begin{array}{l}\text { Carlo et al } \\
\text { (39) }\end{array}$ & 40 & 43 & $\begin{array}{l}6 \times 10^{6} \mathrm{U} \text { IFN-alpha-2b or } \\
\text { alpha-2a every other day for } \\
6 \text { months; then } 3 \times 10^{6} \mathrm{U} \\
\text { every other day for } 6 \text { months }\end{array}$ & $12(30)$ & $20(47)$ & $6(15)$ & $12(28)$ & $\begin{array}{c}18(45) \\
8(20)\end{array}$ & $\begin{array}{l}24(56) \\
16(37)\end{array}$ \\
\hline $\begin{array}{l}\text { Fong et al } \\
\text { (38) }\end{array}$ & 21 & 17 & $\begin{array}{l}3 \times 10^{6} \cup \text { IFN-alpha- } 2 \mathrm{~b} \\
3 \text { times weekly for } 6 \text { months }\end{array}$ & $6(29)$ & $7(41)$ & $1(5)$ & $5(29)$ & $\begin{array}{l}6(29) \\
1(5)\end{array}$ & $\begin{array}{l}9(53) \\
6(35)\end{array}$ \\
\hline
\end{tabular}

examining adjuvant therapy using phlebotomy with interferon treatment (Table 1). Fontana et al (36) randomly assigned 82 previously untreated $\mathrm{CHC}$ patients to either interferon therapy alone, or iron depletion before and during interferon therapy. The group treated with iron depletion and interferon had significantly lower mean HCV RNA levels at treatment weeks 4 and 12 compared with the group treated with interferon alone $(\mathrm{P}<0.05)$. There was also a trend toward improved SVR in patients with pre-interferon phlebotomy treatment (36). Fargion et al (37) studied the response to therapy with either interferon alone or phlebotomy followed by interferon in $114 \mathrm{HCV}$ RNA-positive patients who had hepatic iron concentrations of $700 \mu \mathrm{g} / \mathrm{g}$ or greater (dry weight) in men and $500 \mu \mathrm{g} / \mathrm{g}$ or greater (dry weight) in women. There was a trend toward improved SVR in patients who underwent iron depletion before interferon therapy, particularly in patients with low baseline hepatic iron concentrations $(\mathrm{P}=0.059)$ (37). Fong et al (38) demonstrated that a reduction in serum ferritin and alanine aminotransferase with phlebotomy therapy was not accompanied by a reduction in HCV RNA levels. However, an SVR was achieved in five of 17 (29\%) phlebotomized patients compared with one of 21 controls $(4.8 \%)$ $(\mathrm{P}=0.07)$. This was also observed by Carlo et al (39), with a complete and sustained response in 12 of 39 phlebotomized patients compared with six of 37 controls $(P<0.05)$. In contrast, Piperno et al (40) found no improvement in the end treatment virological response to interferon therapy in 20 patients treated with iron depletion and interferon therapy. A recent meta-analysis (41) of six prospective randomized trials reported an SVR in $27 \%$ of patients in the phlebotomy/interferon group compared with $12 \%$ in the interferon monotherapy group (OR 2.7; 95\% CI 1.6 to 4.5; P<0.0001). In summary, iron depletion in conjunction with interferon monotherapy appears to be associated with an improved SVR, although overall response rates are lower than with interferon/ ribavirin combination therapy (3).
Effect of adjuvant phlebotomy with interferon therapy in nonresponders

Given the favourable treatment outcomes with phlebotomy before interferon therapy in treatment-naive individuals, iron depletion as an adjuvant to interferon therapy has been investigated in CHC patients who did not previously respond to interferon therapy (Table 2). Di Bisceglie et al (42) conducted a study that included 96 subjects - the largest randomized trial to date. There was no improvement in the SVR rate of patients treated with iron depletion by phlebotomy and retreatment with interferon compared with patients treated with iron depletion by phlebotomy alone. However, treatment with phlebotomy and interferon decreased the extent of liver injury, with some improvement in necroinflammatory parameters on liver biopsy (mean index 8.59 versus $7.37 ; \mathrm{P}<0.05)(42)$. A lack of an SVR was also observed in a pilot study (43) involving patients who previously failed to respond to a three-month course of interferon. However, both studies observed a complete biochemical response or normalization of alanine aminotransferase (ALT) levels in $9 \%$ and $18 \%$ of patients, respectively. This was also observed in a study at our centre in 18 previous nonresponders treated with iron depletion by phlebotomy followed by interferon retreatment. Twenty-two per cent of patients had a biochemical response, but no significant change in $\mathrm{HCV}$ RNA was observed (44). In contrast, a study by Tsai et al (45) found a small SVR of $15 \%$ with interferon monotherapy in previous nonresponders treated with phlebotomy. Van Thiel et al (46) found an SVR of 60\% (nine of 15; P not reported) in previous nonresponders retreated with phlebotomy, and an increased dose and frequency of interferon. The role of iron depletion therapy in individuals with previous interferon treatment remains unclear.

SVR after interferon and ribavirin combination therapy in individuals with $\mathrm{HFE}$ mutations and $\mathrm{CHC}$

Despite the evidence of increased iron loading in individuals 


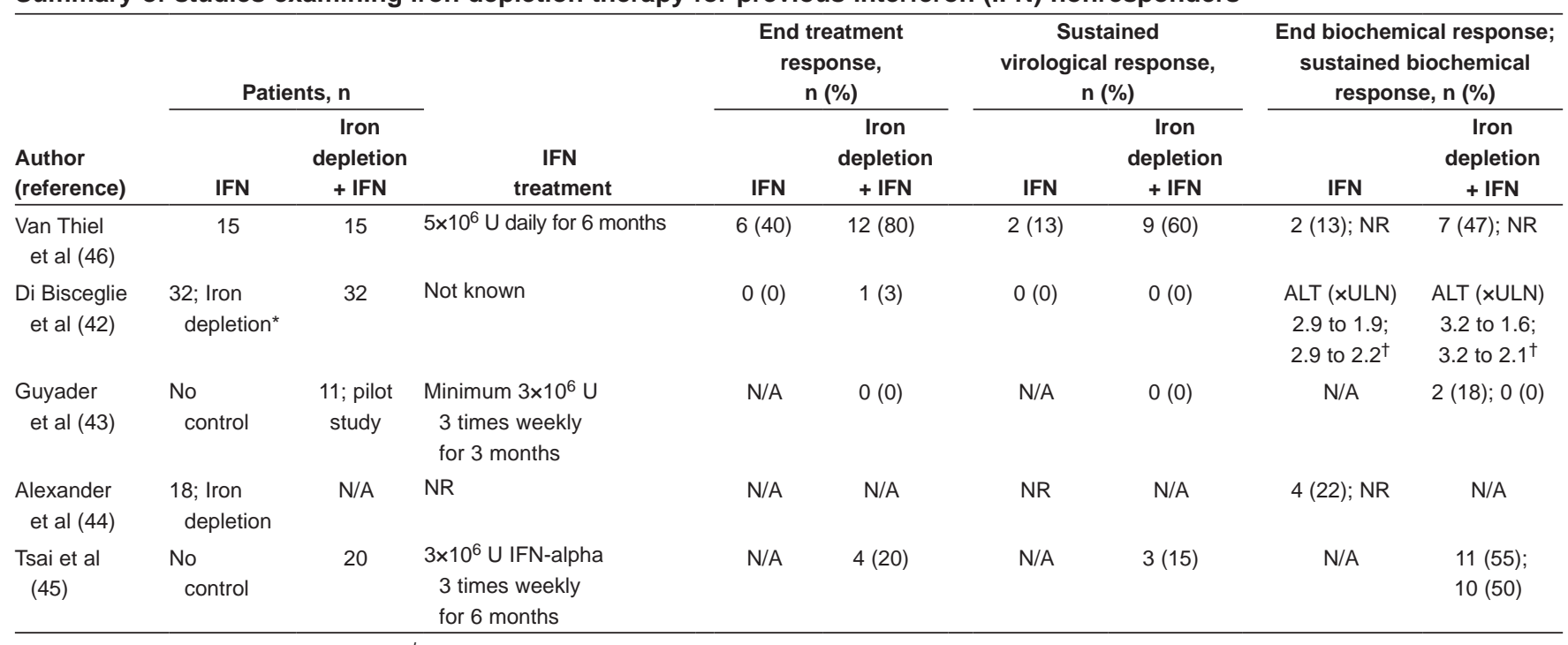

*Iron depletion only (not interferon alone). ${ }^{\dagger} 24$ weeks after treatment. ALT Alanine aminotransferase, N/A Not applicable; NR Not reported; ULN Upper limit of normal

with concurrent $\mathrm{CHC}$ and HFE mutations, the role of phlebotomy with combination interferon/ribavirin therapy has not been investigated in this group of individuals. Bonkovsky et al (15) enrolled 363 advanced CHC patients with HFE mutations who did not previously respond to interferon, with or without ribavirin, into a study using pegylated interferon and ribavirin. They found that $33 \%$ of individuals with HFE mutations demonstrated an end-of-treatment response, and 16\% of those treated with pegylated interferon alpha-2a and ribavirin demonstrated an SVR. Furthermore, individuals with any HFE mutation, especially H63D, were more likely to achieve an end-of-treatment response (40\% with mutation versus $29 \%$ without mutation; $\mathrm{P}=0.0078$ ) and an SVR (20\% with mutation versus $14 \%$ without mutation; $\mathrm{P}=0.009)$. These individuals exhibited significantly higher hepatic global scores than those lacking HFE mutations. Furthermore, the presence of HFE mutations was associated with an increased SVR compared with those without HFE mutations (15). In contrast, increased stainable iron in the portal triads and endothelial cells $(\mathrm{P}<0.0006$ and $\mathrm{P}=0.0083$, respectively $)$ and triad iron score $(\mathrm{P}=0.0018)$ exhibited a significant inverse association with an SVR (15). The authors suggested that the location of iron deposition may be more important than the concentration (15). By contrast, a smaller study with 34 patients (47) found that individuals with HFE mutations treated with interferon/ ribavirin were less likely to achieve an SVR (0 of 14 [0\%] with mutation versus six of 20 [30\%] without mutation; $\mathrm{P}=0.03$ ). While the role of interferon/ribavirin combination therapy in $\mathrm{CHC}$ and HFE mutation carriers appears to be promising, with an increased SVR observed in the HALT-C study, the use of phlebotomy has yet to be further investigated.

\section{Phlebotomy and biochemical response in treatment-naive} patients and nonresponders

Iron depletion with phlebotomy appears to be consistently associated with an improvement in serum ALT levels, suggesting a reduction in hepatic necroinflammation. In a short-term, controlled trial of 33 patients, Yano et al (48) showed that phlebotomy for three months led to a reduction in mean ALT levels from $118 \pm 79 \mathrm{U} / \mathrm{L}$ to $73 \pm 39 \mathrm{U} / \mathrm{L}(\mathrm{P}<0.01)$. A longer, five-year prospective study (49) conducted by the same authors demonstrated a mean ALT reduction from $116.8 \pm 69 \mathrm{U} / \mathrm{L}$ to $74.9 \pm 40.5 \mathrm{U} / \mathrm{L}$ in 25 patients who were initially treated with phlebotomy to reduce ferritin levels to less than $10 \mathrm{ng} / \mathrm{mL}$. Intermittent phlebotomy was performed to a goal ferritin level of less than $20 \mathrm{ng} / \mathrm{mL}$ throughout the five-year study period. The mean time interval between phlebotomy sessions was 8.1 months (range 2.7 to 26 months). The long-term effect of phlebotomy resulted in persistently lower mean ALT levels of $67.3 \mathrm{U} / \mathrm{L}$ $(\mathrm{P}<0.05)$ (49). Several other studies have shown improvement in ALT levels in treatment-naive individuals (36-40,48-50) and nonresponders $(42,43,45)$, with a complete biochemical response of $5 \%$ to $37 \%$ for treatment-naive patients $(36-40)$ and $0 \%$ to $50 \%$ for nonresponders $(42,43,46)$. The complete biochemical response was noted by Fontana et al (36), with ALT normalization in 11 of 40 patients (28\%) 24 weeks after treatment with phlebotomy both before and during interferonalpha-2b therapy (36). A similar biochemical response rate was noted by Fargion et al (37) in 19 of 57 (33\%) patients after six months of follow-up, by Carlo et al (39) in 16 of 43 (37\%) patients one year after follow-up and by Fong et al (38) in six of 17 patients (35\%) after a six-month follow-up. In contrast, Piperno et al (40) found a weak complete biochemical response in treatment-naive patients with a response in one of 20 patients $(5 \%)$, with a one-year follow-up. The complete biochemical response for nonresponders appears controversial and is limited to a few studies. One positive study by Tsai et al (45) with 20 patients who did not previously respond to interferon, reported a sustained biochemical response in 10 of 20 patients $(50 \%)$ after six months of follow-up. However, DiBisceglie et al (42) observed a partial biochemical response in 32 previous nonresponders, with a mean ALT reduction from 3.2 to 2.1 times the upper limit of normal after a one-year follow-up. An absence of complete biochemical response was observed in a small, 11 patient pilot study conducted by Guyader et al (43). Given the evidence that phlebotomy improves serum liver enzymes in both 
treatment-naive and previous nonresponders, it is interesting to speculate that maintenance of an iron depleted state may reduce hepatic necroinflammation in $\mathrm{CHC}$.

\section{Effect of adjuvant phlebotomy with combination interferon and ribavirin therapy}

The role of hepatic iron content in response to combination therapy with interferon and ribavirin remains unclear, and the role of adjuvant phlebotomy remains to be investigated. A report by Fujita et al (11) retrospectively examined $103 \mathrm{HCV}$ infected patients who were treated with interferon/ribavirin for 24 weeks and their total iron liver score, both before and following treatment. Pretreatment total iron score was lower in subjects with SVRs than in nonresponders $(4.39 \pm 3.27$ versus $7.69 \pm 5.76$, respectively; $\mathrm{P}=0.0310$ ), and an elevated total iron score was the only independent variable associated with resistance to interferon/ribavirin $(\mathrm{P}=0.0277)$. Other studies have shown that pretreatment liver iron concentration does not predict response to combination interferon/ribavirin therapy in patients with CHC. Hofer et al (51) measured HIC from liver biopsies in 169 patients with CHC. Nonresponders had higher serum ferritin levels at baseline $(\mathrm{P}<0.01)$, but there was no difference in hepatic iron concentration or transferrin saturation levels between individuals with an SVR and nonresponder patients. A retrospective study by our group (52) investigated $\mathrm{HIC}$ in 112 patients treated with interferon or pegylated interferon that revealed no association between pretreatment hepatic iron concentration and response to combination therapy. Factors associated with an SVR included HCV genotype 2 or 3 (OR 12.2; 95\% CI 3.1 to 47.8) and viral load (less than $2 \times 10^{6}$ copies/mL; OR 3.6; 95\% CI 1.3 to 10$)$. Finally, Pianko et al (53) also found no difference between the hepatic iron concentration in nonresponders and responders $(533 \pm 86 \mu \mathrm{g} / \mathrm{g}$ dry weight versus $662 \pm 95 \mu \mathrm{g} / \mathrm{g}$ dry weight; P not significant). These studies suggest that measurement of iron or hepatic iron concentration may not be of clinical value in predicting response to combination interferon/ribavirin therapy.

\section{Phlebotomy and HCC}

It has been proposed that patients with HCV-related cirrhosis may be predisposed to the development of HCC as a result of hepatic iron loading. Transgenic mice expressing the HCV polyprotein, and nontransgenic littermates fed either an excess iron diet or control diet, were studied by Takakazu et al (54) to determine whether iron overload contributes to the development of HCC. Transgenic mice fed the excess iron diet showed marked hepatic steatosis and ultrastructural alterations of the mitochondria at six months and greater hepatic content of 8-OHdG at 12 months following initiation of the iron-rich diet. Hepatic tumours developed in five of 11 (45\%) transgenic mice fed the excess iron diet for 12 months. However, only three of 11 (27\%) transgenic mice specifically had HCC (54).

In $\mathrm{CHC}$ patients with cirrhosis, Chapoutot et al (55) observed that liver iron deposition was more frequent in patients with $\mathrm{CHC}$ and $\mathrm{HCC}$ than in $\mathrm{CHC}$ controls without HCC (OR 4.94; 95\% CI 1.59 to $15.32 ; \mathrm{P}=0.0056)$, and that the liver iron overload was sinusoidal (OR 5.2; 95\% CI 1.82 to $15.11 ; \mathrm{P}=0.0022$ ). Sinusoidal iron was found exclusively in the periphery of nodules in $27.1 \%$ of HCC patients compared with $16 \%$ of controls, centronodular in $8.3 \%$ versus $21.5 \%$ of controls and diffuse in $37.5 \%$ versus $12.5 \%$ of controls $(\mathrm{P}=0.002)(55)$. Furthermore, histological iron scores including parenchymal hepatocytic, mesenchymal sinusoidal and portal scores were higher in HCC patients than in controls (55). Ko et al (56) investigated the prevalence of hepatic iron overload and HCC in 5224 patients with end-stage liver disease of diverse etiology undergoing liver transplantation. They found that $\mathrm{HCC}$ was strongly associated with stainable hepatic iron in $\mathrm{CHC}$ patients with end-stage liver disease $(\mathrm{P}<0.001)$. Given the finding that increased hepatic iron may predispose individuals to HCC, one study by Kato et al (57) examined the effect of iron depletion on HCC risk in patients with biopsyproven moderate to severe liver fibrosis who could not tolerate or failed to respond to interferon therapy. Thirty-five patients underwent weekly phlebotomy and consumed a low-iron diet until a mild, iron-deficient state was achieved, while the control group consisting of 40 patients declined iron depletion therapy. All patients in the treatment group demonstrated a reduction in serum ALT compared with the control group (to less than $60 \mathrm{U} / \mathrm{L}$ for all patients; ALT normalization in 24 of 35 patients [69\%]). Hepatocarcinogenesis rates in the 10 th year of the study were $8.6 \%$ for the phlebotomy group versus $39 \%$ for the control group, and multivariate analysis revealed that iron depletion therapy was independently associated with a reduction in the risk of HCC, with an OR of 0.57 ( $\mathrm{P}=0.0337)(57)$.

Finally, it has been proposed that iron overload in the liver may lead to oxidative DNA damage and mutagenesis, and HCC. In theory, iron depletion may decrease the accumulation of $8-\mathrm{OHdG}$, a mutagenic byproduct of oxidative DNA damage. One study by Kato et al (58) demonstrated a mean decrease in 8-OHdG levels in nonresponders treated with phlebotomy, with a change in the number of $8-\mathrm{OHdG}$ molecules $/ 10^{5} \mathrm{dG}$ in DNA from $8.3 \pm 4.6 / 10^{5}$ to $2.2 \pm 0.9 / 10^{5}$. Furthermore, a study by Tanaka et al (59) demonstrated an association between increased 8-OHdG and HCC. One hundred eighteen individuals with $\mathrm{CHC}$ and no history of antiviral therapy were found to have higher hepatic $8-\mathrm{OHdG}$ expression levels in patients identified to have HCC on liver biopsy than those without HCC $\left(65.2 \pm 20.2\right.$ versus $40 \pm 23.5$ positive cells $/ 10^{5} \mu^{2}$; $\mathrm{P}<0.0001)$. These studies are intriguing and warrant additional trials of iron depletion to reduce $\mathrm{HCC}$ risk in $\mathrm{CHC}$ patients with cirrhosis, at least in those with increased hepatic iron stores.

\section{ALTERNATIVE TREATMENT MODALITIES WITH A LOW-IRON DIET}

Given the possible beneficial effects of adjuvant iron depletion therapy via phlebotomy, some authors have examined iron restriction with low-iron diet regimens. Tandon et al (60) studied 19 hepatitis B and C patients with either baseline normal or elevated iron levels, and treated them with a 50\% reducediron, rice- and casein-based diet. All patients were compliant and demonstrated significant reduction in serum iron $(\mathrm{P}<0.001)$, transferrin iron saturation $(\mathrm{P}<0.001)$ and ALT levels $(\mathrm{P}<0.05)$ for both groups. A larger randomized trial of 40 patients by Sumida et al (61) compared phlebotomy with a low-iron diet. There was a significant reduction in serum ALT in both groups, but the per cent change in serum ALT was greater for the phlebotomy group than the diet group (median -47.1 versus -24.2 ; $\mathrm{P}<0.001$ ) (61). ALT reduction occurred in $80 \%$ of low-iron diet 
patients and $100 \%$ of phlebotomy patients, with both groups demonstrating significant reduction in serum ferritin levels (61). A low-iron diet may be an alternative approach to reducing body iron stores in $\mathrm{CHC}$ patients.

\section{SUMMARY}

Iron depletion therapy via phlebotomy is associated with improvement of serum ALT levels in both treatment-naive patients and previous nonresponders. Several studies suggest that a combination of phlebotomy and interferon leads to improved SVR in treatment-naive but not treatment-resistant individuals; however, the benefit of iron depletion appears to be restricted to patients receiving interferon monotherapy. There is considerable evidence suggesting that $\mathrm{CHC}$ patients with heterozygous $\mathrm{H} 63 \mathrm{D}$ and, particularly, heterozygous $\mathrm{C} 282 \mathrm{Y}$ mutations are at higher risk of developing fibrosis and cirrhosis of the liver, presumably because of increased hepatic iron deposition. This risk is considerably increased among individuals who are C282Y homozygotes. Phlebotomy therapy is clearly appropriate for patients who express a hemochromatosis phenotype based on hepatic iron measurement or hepatic iron staining. Iron depletion by phlebotomy does not appear to improve the SVR with interferon and ribavirin combination therapy. Furthermore, increased hepatic iron stores do not reduce the likelihood of an SVR with combination therapy. There are limited but intriguing data suggesting that maintenance of an iron-depleted state may stabilize hepatic fibrosis and reduce the incidence of HCC. However, long-term prospective trials are needed to establish the efficacy of phlebotomy therapy for this purpose. In the meantime, we believe that reducing excess body iron stores via phlebotomy or low-iron diet is a reasonable approach in $\mathrm{CHC}$ patients with increased hepatic iron stores and advanced hepatic fibrosis, especially if they are not candidates for treatment with interferon and ribavirin. Such an approach has low risk and may theoretically decrease the rate of disease progression and HCC.

FUNDING: This study was supported, in part, by grant DK-02957 from the National Institutes of Health, Bethesda, Maryland, USA to Dr Kris V Kowdley.

\section{REFERENCES}

1. Disease burden from hepatitis C in the US. <http://www.cdc.gov/ hepatitis/Statistics.htm> (Version current at June 24, 2008).

2. Hepatitis C. <www.who.int/mediacentre/factsheets/fs164/en/> (version current at October 1, 2000).

3. McHutchinson JG, Gordon SC, Schiff ER, et al. Interferon alfa-2b alone or in combination with ribavirin as initial treatment for chronic hepatitis C. N Engl J Med 1998;339:1485-92.

4. Thursz M. Iron, haemochromatosis and thalassaemia as risk factors for fibrosis in hepatitis C virus infection. Gut 2007;56:613-4.

5. Fujita N, Sugimoto R, Ma N, et al. Comparison of hepatic oxidative DNA damage in patients with chronic hepatitis B and C. J Viral Hepatol 2008;15:498-507.

6. Martinelli AL, Ramalho LN, Zucoloto S. Hepatic stellate cells in hepatitis $\mathrm{C}$ patients: Relationship with liver iron deposits and severity of liver disease. J Gastroenterol Hepatol 2004;19:91-8.

7. Nishina S, Hino K, Korenaga M, et al. Hepatitis C virus-induced reactive oxygen species raise hepatic iron level in mice by reducing hepcidin transcription. Gastroenterology 2008;134:226-38.

8. Trinder D, Ayonrinde OT, Olynyk JK. HCV, iron, and oxidative stress: The new choreography of hepcidin. Gastroenterology 2008;134:348-51.
9. Fujita N, Sugimoto R, Takeo M, et al. Hepcidin expression in the liver: Relatively low level in patients with chronic hepatitis C. Mol Med 2007; 13:97-104.

10. Bonkovsky HL, Banner BF, Rothman AL. Iron and chronic viral hepatitis. Hepatology 1997;25:759-68.

11. Fujita N, Sugimotot R, Urawa N, et al. Hepatic iron accumulation is associated with disease progression and resistance to interferon/ ribavirin combination therapy in chronic hepatitis $\mathrm{C}$. J Gastroenterol Hepatol 2007;22:1886-93.

12. Di Bisceglie AM, Axiotis CA, Hoofnagle JH, Bacon BR. Measurements of iron status in patients with chronic hepatitis. Gastroenterology 1992;102:2108-13.

13. Hezode C, Cazeneuve C, Coue O, et al. Liver iron accumulation in patients with chronic active hepatitis C: Prevalence and role of hemochromatosis gene mutations and relationship with hepatic histological lesions. J Hepatol 1999;31:979-84.

14. Olynyk JK, Reddy KR, Di Bisceglie AM, et al. Hepatic iron concentration as a predictor of response to interferon-alfa therapy in chronic hepatitis C. Gastroenterology 1995;108:1104-9.

15. Bonkovsky HL, Naishadham D, Lambreacht RW, et al. Roles of iron and HFE mutations on severity and response to therapy during retreatment of advanced chronic hepatitis C. Gastroenterology 2006;131:1440-51.

16. Tung BY, Emond MJ, Bronner MP, Raaka SD, Cotler SJ, Kowdley KV. Hepatitis C, iron status, and disease severity: Relationship with HFE mutations. Gastroenterology 2003;124:318-26.

17. Smith BC, Grove J, Guzail MA, et al. Heterozygosity for hereditary hemochromatosis is associated with more fibrosis in chronic hepatitis C. Hepatology 1998;27:1695-9.

18. Piperno A, Vergani A, Malosio D, et al. Hepatic iron overload in patients with chronic viral hepatitis: Role of HFE gene mutations. Hepatology 1998;28:1105-9.

19. Bonkovsky HL, Troy N, McNeal K, et al. Iron and HFE or TfR1 mutations as comorbid factors for development and progression of chronic hepatitis C. J Hepatol 2002;37:848-54.

20. Kazemi-Shirazi L, Datz C, Maier-Dobersberger T, et al. The relation of iron status and hemochromatosis gene mutations in patients with chronic hepatitis C. Gastroenterology 1999;116:127-34.

21. Erhardt A, Maschner-Olberg A, Mellenthin C, et al. HFE mutations and chronic hepatitis C: H63D and C282Y heterozygosity are independent risk factors for liver fibrosis and cirrhosis. J Hepatol 2003;38:335-42.

22. Gehrke S, Stremmel W, Mathes I, Riedel H, Bents K, Kallinowski B. Hemochromatosis and transferrin receptor gene polymorphisms in chronic hepatitis C: Impact on iron status, liver injury, and HCV genotype. J Mol Med 2003;81:780-7.

23. Geier A, Reugels M, Weiskirchen R, et al. Common heterozygous hemochromatosis gene mutations are risk factors for inflammation and fibrosis in chronic hepatitis C. Liv Int 2004;24:285-94.

24. Thorburn D, Curry G, Spooner R, et al. The role of iron and haemochromatosis gene mutations in the progression of liver disease in chronic hepatitis C. Gut 2002;50:248-52.

25. Lal P, Fernandes H, Koneru B, Albanese E, Hameed M. C282Y mutation and hepatic iron status in hepatitis $\mathrm{C}$ and cryptogenic cirrhosis. Arch Pathol Lab Med 2000;124:1632-5.

26. Pirisi M, Scott CA, Avellini C, et al. Iron deposition and progression of disease in chronic hepatitis C. Am J Clin Pathol 2000;113:546-54.

27. Negro F, Samii K, Rubbia-Brandt L, et al. Hemochromatosis gene mutations in chronic hepatitis $\mathrm{C}$ patients with and without liver siderosis. J Med Virol 2000;60:21-7.

28. Hohler T, Leininger S, Kohler HH, Schirmacher P, Galle PR. Heterozygosity for the hemochromatosis gene in liver diseases prevalence and effects on liver histology. Liver 2000;20:482-6.

29. Cauza E, Peck-Radosavljevic M, Ulrich-Pur H, et al. Mutations of the HFE gene in patients with hepatocellular carcinoma. Am J Gastroenterol 2003;98:442-7.

30. Hellerbrand C, Poppl A, Hartmann A, Scholmerich J, Lock G. HFE C282Y heterozygosity in hepatocellular carcinoma: Evidence for an increased prevalence. Clin Gastroenterol Hepatol 2003;1:279-84.

31. Lauret E, Rodriguez M, Gonzalez S, et al. HFE gene mutations in alcoholic and virus-related cirrhotic patients with hepatocellular carcinoma. Am J Gastroenterol 2002;97:1016-21. 
32. Boige V, Castera L, de Roux N, et al. Lack of association between HFE gene mutations and hepatocellular carcinoma in patients with cirrhosis. Gut 2003;52:1178-81.

33. Kowdley KV. Iron, hemochromatosis, and hepatocellular carcinoma. Gastroenterology 2004;127:S79-S86.

34. Van Thiel DH, Friedlander L, Fagiuoli S, Wright HI, Irish W, Gavaler JS. Response to interferon alpha therapy is influenced by the iron content of the liver. J Hepatol 1994;20:410-15.

35. Ikura Y, Morimoto H, Johmura H, Fukui M, Sakurai M. Relationship between hepatic iron deposits and response to interferon in chronic hepatitis C. Am J Gastroenterol 1996;91:1367-73.

36. Fontana RJ, Israel J, LeClair P, et al. Iron reduction before and during interferon therapy of chronic hepatitis C: Results of a multicenter, randomized, controlled trial. Hepatology 2000;31:730-6.

37. Fargion S, Fracanzani AL, Rossini A, et al. Iron reduction and sustained response to interferon-alpha therapy in patients with chronic hepatitis C: Results of an Italian multicenter randomized study. Am J Gastroenterol 2002;97:1204-10.

38. Fong TL, Han SH, Tsai NC, et al. A pilot randomized, controlled trial of the effect of iron depletion on long-term response to alphainterferon in patients with chronic hepatitis C. J Hepatol 1998;28:369-74.

39. Carlo C, Daniela P, Giancarlo C. Iron depletion and response to interferon in chronic hepatitis C. Hepatol Gastroenterol 2003;50:1467-71.

40. Piperno A, Sampietro M, D'Alba R, et al. Iron stores, response to alpha-interferon therapy, and effects of iron depletion in chronic hepatitis C. Liver 1996;16:248-54.

41. Desai TK, Jamil LH, Balasubramaniam M, Koff R, Bonkovsky HL. Phlebotomy improves therapeutic response to interferon in patients with chronic hepatitis C: A meta-analysis of six prospective randomized controlled trials. Dig Dis Sci 2008;53:815-22.

42. Di Bisceglie AM, Bonkovsky HL, Chopra S, et al. Iron reduction as an adjuvant to interferon therapy in patients with chronic hepatitis $\mathrm{C}$ who have previously not responded to interferon: A multicenter, prospective, randomized, controlled trial. Hepatology 2000;32:135-8.

43. Guyader D, Boucher E, Andre P, et al. A pilot study of iron depletion as adjuvant therapy in chronic hepatitis $\mathrm{C}$ patients not responding to interferon. Am J Gastroenterol 1999;94:1696-8.

44. Alexander J, Tung BY, Croghan A, Kowdley KV. Effect of iron depletion on serum markers of fibrogenesis, oxidative stress and serum liver enzymes in chronic hepatitis C: Results of a pilot study. Liver Int 2007;27:268-73.

45. Tsai N, Zuckerman E, Han SH, Goad K, Redeker AG, Fong TL. Effect of iron depletion on long-term response to interferon-alpha in patients with chronic hepatitis $\mathrm{C}$ who previously did not respond to interferon therapy. Am J Gastroenterol 1997;92:1831-4.

46. Van Thiel DH, Friedlander L, Molloy PJ, et al. Retreatment of hepatitis $\mathrm{C}$ interferon non-responders with larger doses of interferon with and without phlebotomy. Hepatogastroenterology 1996:43:1557-61.

47. Coelho-Borges S, Cheinquer H, Cheinquer N, Krug L, Ashton-Prollo P. HFE gene mutations prevent sustained virological response to interferon plus ribavirin in chronic hepatitis $\mathrm{C}$ patients with serum markers of iron overload. AJG 2002;97:1570-2.

48. Yano M, Hayashi $\mathrm{H}$, Yoshioka $\mathrm{K}$, et al. A significant reduction in serum alanine aminotransferase levels after 3 -month iron reduction therapy for chronic hepatitis C: A multicenter, prospective, randomized, controlled trial in Japan. J Gastroenterol 2004;39:570-4.

49. Yano M, Hayashi H, Wakusawa S, et al. Long term effects of phlebotomy on biochemical and histological parameters of chronic hepatitis C. Am J Gastroenterol 2002;97:133-7.

50. Kawamura Y, Akuta N, Sezaki H, et al. Determinants of serum ALT normalization after phlebotomy in patients with chronic hepatitis $\mathrm{C}$ infection. J Gastroenterol 2005;40:901-6.

51. Hofer H, Osterreicher C, Jessner W, et al. Hepatic iron concentration does not predict response to standard and pegylated-IFN/ribavirin therapy in patients with chronic hepatitis C. J Hepatol 2004;40:1018-22.

52. Rulyak SJ, Eng SC, Patel K, McHutchinson JG, Gordon SC, Kowdley K. Relationships between hepatic iron content and virologic response in chronic hepatitis $\mathrm{C}$ patients treated with interferon and ribavirin. Am J Gastroenterol 2005;100:332-7.

53. Pianko S, McHutchison JG, Gordon SC, et al. Hepatic iron concentration does not influence response to therapy with interferon plus ribavirin in chronic HCV infection. J Interferon Cytokine Res 2002;22:483-9.

54. Takakazu F, Keisuke H, Michiari O, et al. Hepatic iron overload induces hepatocellular carcinoma in transgenic mice expressing the hepatitis C virus polyprotein. Gastroenterology 2006;130:2087-98.

55. Chapoutot C, Esslimani M, Joomaye Z, et al. Liver iron excess in patients with hepatocellular carcinoma developed on viral C cirrhosis. Gut 2000;46:711-4.

56. Ko C, Siddaiah N, Berger J, et al. Prevalence of hepatic iron overload and association with hepatocellular cancer in end-stage liver disease: Results from the National Hemochromatosis Transplant Registry. Liv Int 2007;27:1394-1401.

57. Kato J, Miyanishi K, Kobune M, et al. Long-term phlebotomy with low-iron diet therapy lowers risk of development of hepatocellular carcinoma from chronic hepatitis C. J Gastroenterol 2007;42:830-6.

58. Kato J, Kobune M, Nakamura T, et al. Normalization of elevated hepatic 8-hydroxy-2'-deoxyguanosine levels in chronic hepatitis $\mathrm{C}$ patients by phlebotomy and low iron diet. Cancer Res 2001;61:8697-702.

59. Tanaka H, Fujita N, Sugimoto R, et al. Hepatic oxidative DNA damage is associated with increased risk for hepatocellular carcinoma in chronic hepatitis C. BJC 2008;98:580-6.

60. Tandon N, Thaker V, Kumkar R, Guptan C, Sarin SK. Beneficial influence of an indigenous low-iron diet on serum indicators of iron status in patients with chronic liver disease. British J Nutr 2000;83:235-9.

61. Sumida Y, Kanemasa K, Fukumoto K, Yoshida N, Sakai K. Effects of dietary iron reduction versus phlebotomy in patients with chronic hepatitis C: Results from a randomized, controlled trial on 40 Japanese patients. Intern Med 2007;46:637-42. 


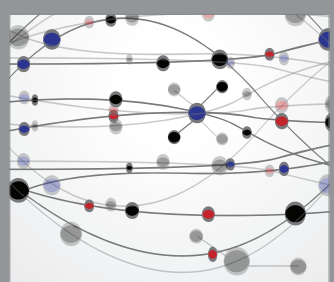

The Scientific World Journal
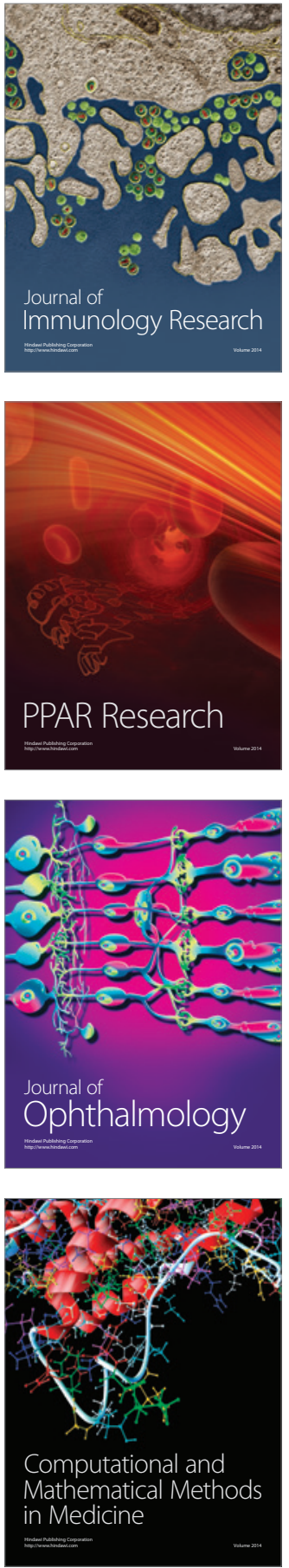

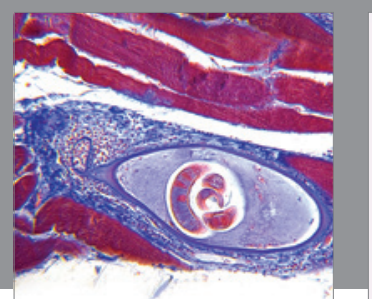

Gastroenterology Research and Practice

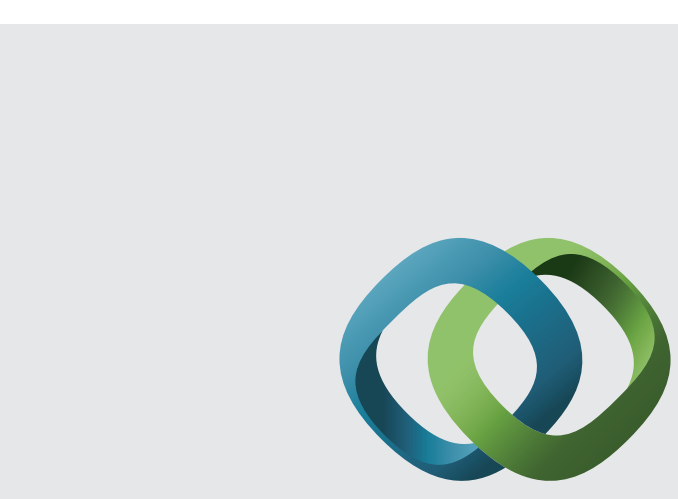

\section{Hindawi}

Submit your manuscripts at

http://www.hindawi.com
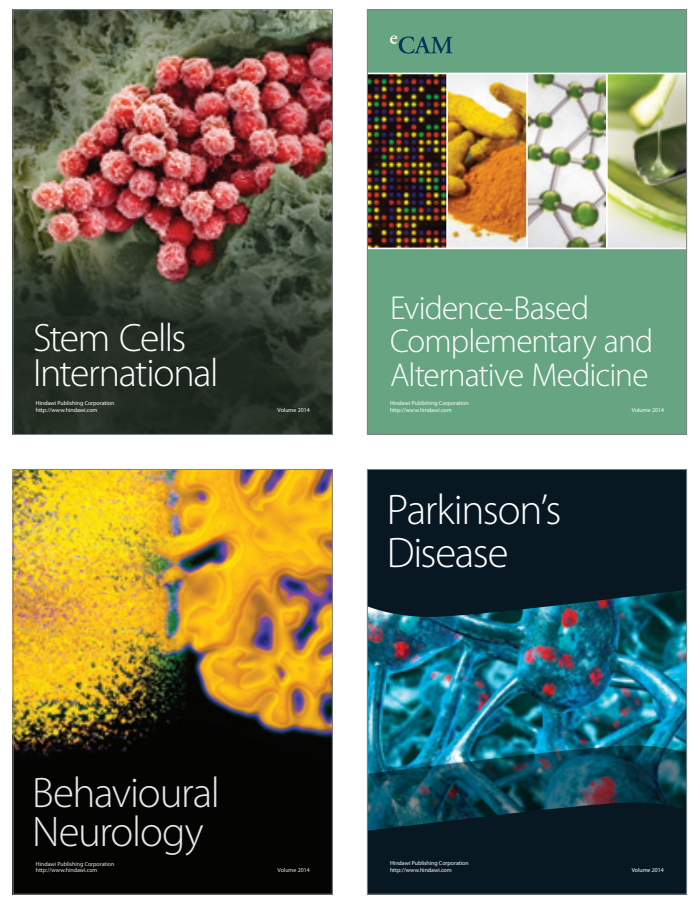
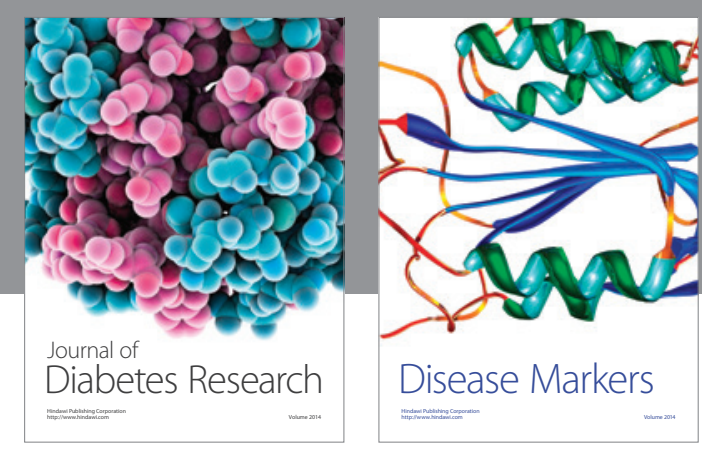

Disease Markers
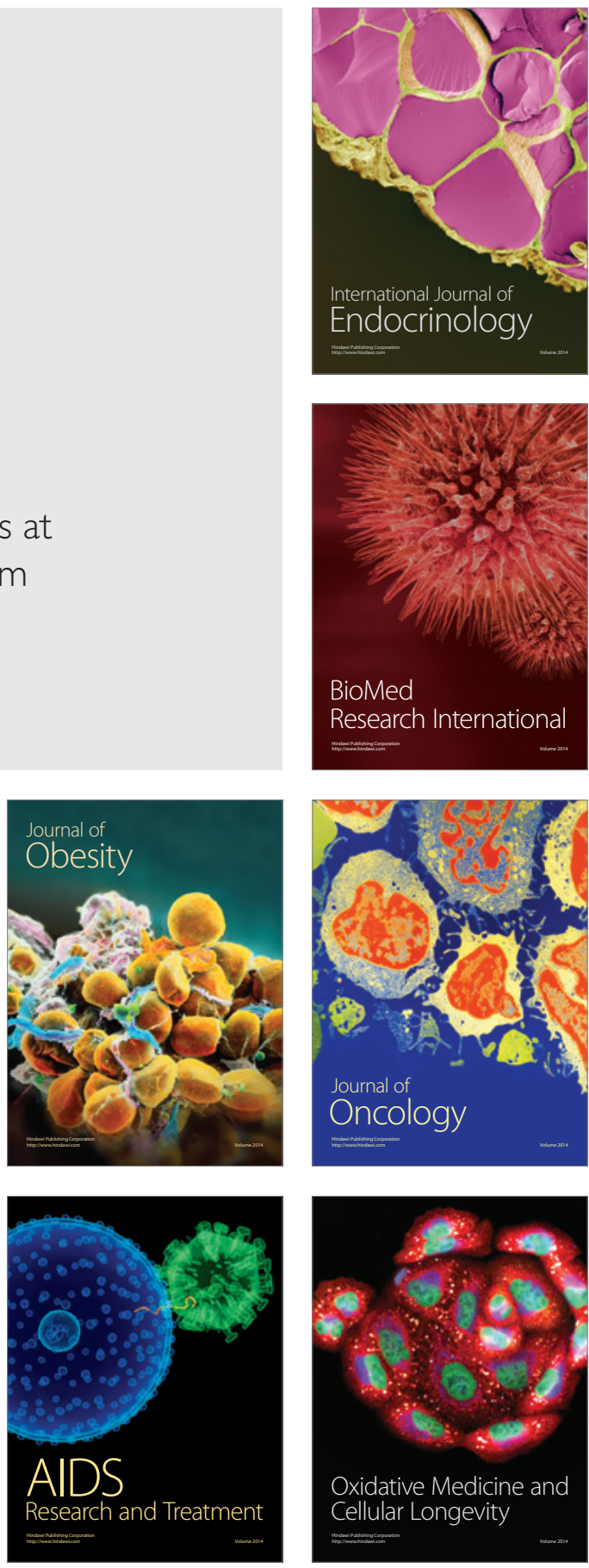